\title{
Antifungal Activities of Volatile Secondary Metabolites of Four Diaporthe Strains Isolated from Catharanthus roseus
}

\author{
Dong-Hui Yan ${ }^{1, *}$, Xiaoyu Song ${ }^{1}$, Hongchang $\mathrm{Li}^{1}{ }^{1}$, Tushou Luo ${ }^{2}$, Guiming Dou ${ }^{1}$ and \\ Gary Strobel ${ }^{3, *}$ \\ 1 Research Institute of Forest Ecology, Environment and Protection, Chinese Academy of Forestry, \\ Hai Dian District, Beijing 100091, China; songxiaoyucaf@gmail.com (X.S.); lhc1994224@163.com (H.L.); \\ dgmgogogo@126.com (G.D.) \\ 2 Research Institute of Tropical Forestry, Chinese Academy of Forestry, Tianhe District, \\ Guangzhou 510520, China; luots@126.com \\ 3 Department of Plant Sciences, Montana State University, Bozeman, MT 59717, USA \\ * Correspondence: yandh@caf.ac.cn (D.-H.Y.); uplgs@montana.edu (G.S.); \\ Tel.: +86-10-6288-9270 (D.-H.Y.); +1-406-994-5148 (G.S.)
}

Received: 1 May 2018; Accepted: 29 May 2018; Published: 30 May 2018

\begin{abstract}
Four endophytic fungi were isolated from the medicinal plant, Catharanthus roseus, and were identified as Diaporthe spp. with partial translation elongation factor 1-alpha (TEF1), beta-tubulin (TUB), histone H3 (HIS), calmodulin (CAL) genes, and rDNA internal transcribed spacer (ITS) region (TEF1-TUB-HIS-CAL-ITS) multigene phylogeny suggested for species delimitation in the Diaporthe genus. Each fungus produces a unique mixture of volatile organic compounds (VOCs) with an abundant mixture of terpenoids analyzed by headspace solid-phase microextraction (SPME) fiber-GC/MS. These tentatively-detected terpenes included $\alpha$-muurolene, $\beta$-phellandrene, $\gamma$-terpinene, and $\alpha$-thujene, as well as other minor terpenoids, including caryophyllene, patchoulene, cedrene, 2-carene, and thujone. The volatile metabolites of each isolate showed antifungal properties against a wide range of plant pathogenic test fungi and oomycetes, including Alternaria alternata, Botrytis cinerea, Colletotrichum gloeosporioides, Fusarium graminearum, and Phytophthora cinnamomi. The growth inhibition of the pathogens varied between $10 \%$ and $60 \%$ within $72 \mathrm{~h}$ of exposure. To our knowledge, the endophytic Diaporthe-like strains are first reported from Catharanthus roseus. VOCs produced by each strain of the endophytic Diaporthe fungi were unique components with dominant monoterpenes comparing to known Diaporthe fungal VOCs. A discussion is presented on the inhibitive bioactivities of secondary metabolites among endophytic Diaporthe fungi and this medicinal plant.
\end{abstract}

Keywords: endophytic fungi; Diaporthe spp.; Catharanthus roseus; volatile organic compounds (VOCs); antifungal bioactivity; inhibition; terpene; pathogens

\section{Introduction}

Many plants remain unexplored for their endophytic fungi and the potentially important products that they may produce [1]. Catharanthus roseus is known as a pharmaceutical plant containing rich anticancer alkaloids. The extracts of many organs of this plant also exhibit antimicrobial effects [2-6]. It turns out that Catharanthus roseus is host to a diverse group of endophytic fungi [7-10]. Some endopytic fungi were found to produce several metabolites biosynthesized by the host Catharanthus roseus. The endophytic fungi Curvularia sp. CATDLF5 and Choanephora infundibulifera CATDLF6 isolated from leaf issues were able to enhance leaf vindoline production content of $C$. roseus cv. 
prabal by $2.29-4.03$ times through root inoculation [8]. Endophytic Fusarium spp. from stem issues seemed to facilitate the host plant to produce secondary metabolites [9]. Additionally, some endophytic fungi from the plant produced antimicrobial compounds. For example, the compounds hydroxyemodin, citreoisocoumarin, citreoisocoumarinol, and cladosporin from endophytic fungi of leaves were effective in inhibiting fungal pathogens [10]. Diaporthe are commonly found as endophytes in a wide range of plants around the world [11-15]. These endophytes are prolific producers of antimicrobial metabolites $[15,16]$. D. endophytica and D. terebinthifolii, isolated from the medicinal plants Maytenus ilicifolia and Schinus terebinthifolius, had an inhibitory effect against Pseudomonas citricarpa in vitro and in detached fruits [12,13]. The crude extracts of Diaporthe sp. MFLUCC16-0682 and Diaporthe sp. MFLUCC16-0693 exhibited notable antibacterial and antioxidant activities [14]. An endophytic Phomopsis (asexual state of Diaporthe) fungus isolated from the stems of Ficus pumila, exhibited broad-spectrum antimicrobial activity against Gram-positive and Gram-negative human and phytopathogenic bacteria and fungi [15]. Thus, the genus Diaporthe is a potential source of metabolites that can be used in a variety of applications [14]. However, endophytic Diaporthe fungi have not been recorded from Catharanthus roseus to the present.

Volatile organic compounds (VOCs) have noted biofumigative effects especially from the endophytic fungus-Muscodor albus [17]. These observations opened a unique venue for the application of endophytic microorganisms to the ecological-friendly biocontrol of pests [17]. The inhibitive bioactive compounds were also found in a few isolates of endophytic Diaporthe [18]. An endophytic Phomopsis isolate of Odontoglossum sp. in Northern Ecuador was reported to produce a unique mixture of volatile organic compounds (VOCs) with sabinene, 1-butanol, 3-methyl; benzeneethanol; 1-propanol, 2-methyl, and 2-propanone. The VOCs showed antifungal bioactivities on a wide range of plant pathogenic fungi, such as Sclerotinia, Rhizoctonia, Fusarium, Botrytis, Verticillium, Colletotrichum and oomycetes Pythium, and Phytophthora [18]. The PR4 strain of an endophytic Phomopsis obtained from the medicinal plant Picrorhiza kurroa also produced a unique set of bioactive VOCs inhibitive to plant pathogenic fungi growth. The dominant compounds in VOCs of the PR4 strain were reported as menthol, phenylethyl alcohol, isomenthol, $\beta$-phellandrene, $\beta$-bisabolene, limonene, 3 -pentanone and 1-pentanol [19]. In view of the antimicrobial properties of the extracts from the medicinal plant Cantharatus roseus, and limited knowledge on endophytic Diaporthe species in this host, we conducted an investigation on the antifungal bioactivity of VOCs from four endophytic Diaporthe strains isolated from wild Catharanthus roseus in China. The combined sequences of five loci, elongation factor 1-alpha (TEF1), beta-tubulin (TUB), histone H3 (HIS), calmodulin (CAL) genes, and the rDNA internal transcribed spacer (ITS) region were used for the strains' phylogenetic analyses within genus Diaprothe. Inhibitory bioactivity executed volatile organic compounds from the strains were observed on growths of tested plant pathogens in co-culture. Active components of VOCs were analyzed and inferred using headspace solid-phase microextraction (SPME) fiber-GC/MS and based on their reported properties.

\section{Materials and Methods}

\subsection{Endophytic Fungal Isolation}

The four endophytic fungi were isolated from wild plants, Catharanthus roseus, growing in the National Natural Conservation Area of TongGu Mountain, located in Wenchang city of Hainan Province. Several stem segments $(5-10 \mathrm{~cm}$ in length) were collected for the eventual isolation of endophytes. Retrieving endophytic fungi followed a previously described procedure [20]. Briefly, the external tissues of segments were cleaned with tap water and scrubbed with $70 \%$ ethanol prior to excision of internal tissues. Then the segments were excised into smaller fragments about $0.2-0.5 \mathrm{~cm}$ in length. The fragments were thoroughly exposed to $75 \%$ ethanol for $60 \mathrm{~s}, 3 \% \mathrm{NaClO}$ for $90 \mathrm{~s}$, and sterile water for $60 \mathrm{~s}$ by agitation. The fragments at the last step were drained on sterile filter papers and put on water agar in Petri plates for growing endophytes. Further, pure isolates were obtained in potato dextrose agar media and stored on sterilized, inoculated barley seeds at $4{ }^{\circ} \mathrm{C}$ and $-80{ }^{\circ} \mathrm{C}$. 
The four fungi of interest were assigned with our laboratory acquisition number-ID FPYF3053-3056 and deposited in China Forestry Culture Collection Center assigned IDs of CFCC 52704-52707.

\subsection{DNA Extraction, $P C R$, and Sequencing}

Fungal genomic DNA was extracted from colonies growing on PDA for one week with the CTAB procedure [20]. The extracted DNA was further purified through Mini Purification kit (Tiangen Biotech (Beijing) Co., Ltd., Beijing, China) following the manufacture's protocols. The DNA quality and concentration were determined with a NanoDrop 2000 (Thermo Fisher Scientific Inc., Waltham, MA, USA) after the DNA was checked with Genegreen nucleic acid dye (Tiangen Biotech (Beijing) Co., Ltd.) in an electrophoresis on $1 \%$ agarose gel stained under ultraviolet light. The extracted DNA was used as a template for the further PCR amplification ITS sequence and TEF1, CAL, TUB, and HIS genes regions. The primers were used to amplify the ITS targets, namely, the ITS1 and ITS4 [21], TEF1 with EF1-688F/EF1-1251R [22], CAL with CL1F/CL2A or CAL563F/CL2A [23], TUB with T1/Bt-2b or Bt2a/Bt-2b [24,25], and HIS with HISdiaF/HISdiaR, sequences that were 5'-GGCTCCCCGYAAGCAGCTCGCCTCC-3 and 5'-ATYCCGACTGGATGGTCACACGCTTGG-3, respectively. All PCR reaction mixtures and conditions were followed as per the Taq PCR MasterMix kits (Tiangen Biotech (Beijing) Co., Ltd.) according to the manufacture's protocol. A PCR reaction system consisted of $0.5 \mu \mathrm{L}$ of each primer $(10 \mu \mathrm{M}), 3 \mu \mathrm{L}$ (15-80 ng) of DNA template, $12.5 \mu \mathrm{L}$ of $2 \times$ Taq PCR MasterMix (Tiangen Biotech (Beijing) Co., Ltd.), and $8.5 \mu \mathrm{L}$ of double distilled water in total of $25 \mu \mathrm{L}$. The ITS thermal cycling program was as follows: $94{ }^{\circ} \mathrm{C}$ for $5 \mathrm{~min}$, followed by 35 amplification cycles of $94{ }^{\circ} \mathrm{C}$ for $60 \mathrm{~s}, 55^{\circ} \mathrm{C}$ for $30 \mathrm{~s}$ and $72{ }^{\circ} \mathrm{C}$ for $1 \mathrm{~min}$, and a final extension step of $72{ }^{\circ} \mathrm{C}$ for $5 \mathrm{~min}$. The annealing temperature at $55^{\circ} \mathrm{C}$ for $45 \mathrm{~s}$ was changed in this program for $C A L, \beta$-tubulin and TEF amplification. For amplification of HIS, the program was changed with a cycling program of 32 cycles and an annealing temperature at $55^{\circ} \mathrm{C}$ for $60 \mathrm{~s}$. PCR products were visualized on $1.5 \%$ agarose gels mixed with Genegreen Nucleic Acid Dye and purified with a quick Midi Purification kit (Tiangen Biotech (Beijing) Co., Ltd.) according to the manufacturer's instructions. Sequencing PCR products were cycle-sequenced the BigDye ${ }^{\circledR}$ Terminator Cycle Sequencing Kit v. 3.1 (Applied Biosystems, Foster City, CA, USA) in an ABI Prism 3730 DNA Sequencer (Applied Biosystems, Foster City, CA, USA) at Biomed Company in Beijing. Then sequence data collected by ABI 3730 Data collection v. 3.0 (Applied Biosystems, Foster City, CA, USA) and ABI Peak Scanner Software v. 1.0 (Applied Biosystems, Foster City, CA, USA), were assembled with forward and reverse sequences by BioEdit. The gene sequences were submitted and awarded access numbers in GenBank of NCBI (Table 1).

Table 1. Access numbers for ITS, translation elongation factor 1-alpha (TEF1), beta-tubulin (TUB), histone $\mathrm{H} 3(H I S)$, calmodulin $(C A L)$ genes region sequences of the four endophytic Diaporthe fungi in the GenBank of NCBI.

\begin{tabular}{cccccc}
\hline Isolate & ITS & TEF1 & Tublin & CAL & HIS \\
\hline FPYF3053 & MH203054.1 & MH220826.1 & MH220836.1 & MH220831.1 & MH220839.1 \\
FPYF3054 & MH203055.1 & MH220827.1 & MH220833.1 & MH220832.1 & MH220840.1 \\
FPYF3055 & MH203056.1 & MH220828.1 & MH220834.1 & MH220829.1 & MH220837.1 \\
FPYF3056 & MH203057.1 & MH220825.1 & MH220835.1 & MH220830.1 & MH220838.1 \\
\hline
\end{tabular}

\subsection{Sequence Alignment and Phylogenetic Analysis}

In order to determine the phylogenetic locations of the four isolates within the Diaporthe genus, 143 reference taxa [26] (Table 2) together with the four isolates were used for building a phylogenetic a tree with Diaporthella corylina as a root outgroup species [23]. The evolutionary relationships were taken on a five-gene concatenated alignment of ITS, TEF1, CAL, HIS, and TUB regions by maximum likelihood (ML) and maximum parsimony (MP) phylogenetic analyses. Sequences were aligned using the MAFFTv.7 online program with default parameters [27]. A partition homogeneity test implemented in PAUP* v.4.0 (Sinauer Associates, Sunderland, MA, USA) was applied to determine if 
the five sequence data could be combined. The best evolutionary model for the partitioning analysis was performed on the concatenated sequences by PartitionFinder 2.1.1 [28]. A concatenated alignment for the five gene regions was made from SequenceMatrix [29]. The inference methods of maximum likelihood and maximum parsimony in Mega 6.0 [30] were applied to estimate phylogeny for the concatenated sequences, with the evolutionary models GTR and AIC for ML and MP, respectively, with a bootstrap support of 1000 replicates. Evidence on the trees were visualized and edited by TreeGraph 2 [31].

Table 2. Reference sequences of Diaporthe strains with NCBI access numbers for phylogenetic analysis.

\begin{tabular}{|c|c|c|c|c|c|}
\hline Source & ITS & TEF1 & TUB & $C A L$ & HIS \\
\hline Diaporthe acaciigena_CBS 129521 & КС343005.1 & КС343731.1 & KC343973.1 & КС343247.1 & КС343489.1 \\
\hline Diaporthe acerina_CBS 137.27 & КС343006.1 & КС343732.1 & КС343974.1 & КС343248.1 & КС343490.1 \\
\hline Diaporthe alleghaniensis_CBS 495.72 & КС343007.1 & КС343733.1 & КС343975.1 & КС343249.1 & КС343491.1 \\
\hline Diaporthe alnea_CBS $14 \overline{6} .46$ & КС343008.1 & КС343734.1 & КС343976.1 & КС343250.1 & КС343492.1 \\
\hline Diaporthe alnea_CBS 159.47 & КС343009.1 & КС343735.1 & КС343977.1 & КС343251.1 & КС343493.1 \\
\hline Diaporthe ambigua_CBS 114015 & КС343010.1 & КС343736.1 & КС343978.1 & КС343252.1 & КС343494.1 \\
\hline Diaporthe ambigua_CBS 117167 & КС343011.1 & КС343737.1 & КС343979.1 & КС343253.1 & КС343495.1 \\
\hline Diaporthe amygdali_CBS 126679 & КС343022.1 & КС343742.1 & КС343984.1 & КС343258.1 & КС343506.1 \\
\hline Diaporthe ampelina_CBS 111888 & КС343016.1 & КС343748.1 & КС343990.1 & КС343264.1 & КС343500.1 \\
\hline Diaporthe amygdali_CBS 111811 & КС343019.1 & КС343745.1 & KC343987.1 & КС343261.1 & КС343503.1 \\
\hline Diaporthe anacardii_CBS 720.97 & КС343024.1 & КС343750.1 & КС343992.1 & КС343266.1 & КС343508.1 \\
\hline Diaporthe angelicae_CBS 111592 & КС343027.1 & КС343753.1 & КС343995.1 & КС343269.1 & КС343511.1 \\
\hline Diaporthe angelicae_CBS 123215 & КС343028.1 & КС343754.1 & КС343996.1 & КС343270.1 & КС343512.1 \\
\hline Diaporthe cucurbitae_CBS 136.25 & КС343031.1 & КС343757.1 & КС343999.1 & КС343273.1 & КС343515.1 \\
\hline Diaporthe arecae_CBS 161.64 & КС343032.1 & КС343758.1 & КС344000.1 & КС343274.1 & КС343516.1 \\
\hline Diaporthe arecae_CBS 535.75 & КС343033.1 & КС343759.1 & КС344001.1 & КС343275.1 & КС343517.1 \\
\hline Diaporthe arengae_CBS 114979 & КС343034.1 & КС343760.1 & КС344002.1 & КС343276.1 & КС343518.1 \\
\hline Diaporthe aspalathi_CBS 117169 & КС343036.1 & КС343762.1 & КС344004.1 & КС343278.1 & КС343520.1 \\
\hline Diaporthe aspalathi_CBS 117168 & КС343035.1 & КС343761.1 & КС344003.1 & КС343277.1 & КС343519.1 \\
\hline Diaporthe australafricana_CBS 111886 & КС343038.1 & КС343764.1 & КС344006.1 & КС343280.1 & КС343522.1 \\
\hline Diaporthe australafricana_CBS 113487 & КС343039.1 & КС343765.1 & КС344007.1 & КС343281.1 & КС343523.1 \\
\hline Diaporthe batatas_CBS 122.21 & КС343040.1 & КС343766.1 & КС344008.1 & КС343282.1 & КС343524.1 \\
\hline Diaporthe beckhausii_CBS 138.27 & КС343041.1 & КС343767.1 & КС344009.1 & КС343283.1 & КС343525.1 \\
\hline Diaporthe bicincta_CBS 121004 & КС343134.1 & КС343860.1 & КС344102.1 & КС343376.1 & КС343618.1 \\
\hline Diaporthe brasiliensis_CBS 133183 & КС343042.1 & КС343768.1 & КС344010.1 & КС343284.1 & КС343526.1 \\
\hline Diaporthe brasiliensis_LGMF926 & КС343043.1 & КС343769.1 & КС344011.1 & КС343285.1 & КС343527.1 \\
\hline Diaporthe carpini_CBS 114437 & КС343044.1 & КС343770.1 & KC344012.1 & КС343286.1 & КС343528.1 \\
\hline Diaporthe caulivora_CBS 127268 & КС343045.1 & КС343771.1 & КС344013.1 & КС343287.1 & КС343529.1 \\
\hline Diaporthe caulivora_CBS 178.55 & КС343046.1 & КС343772.1 & КС344014.1 & КС343288.1 & КС343530.1 \\
\hline Diaporthe celastrina_CBS 139.27 & КС343047.1 & КС343773.1 & КС344015.1 & КС343289.1 & КС343531.1 \\
\hline Diaporthe chamaeropis_CBS 454.81 & КС343048.1 & КС343774.1 & КС344016.1 & КС343290.1 & КС343532.1 \\
\hline Diaporthe chamaeropis_CBS 753.70 & КС343049.1 & КС343775.1 & КС344017.1 & КС343291.1 & КС343533.1 \\
\hline Diaporthe cinerascens_CBS 719.96 & КС343050.1 & КС343776.1 & КС344018.1 & КС343292.1 & КС343534.1 \\
\hline Diaporthe citri_CBS 199.39 & КС343051.1 & КС343777.1 & КС344019.1 & КС343293.1 & КС343535.1 \\
\hline Diaporthe citri_CBS 230.52 & КС343052.1 & КС343778.1 & КС344020.1 & КС343294.1 & КС343536.1 \\
\hline Diaporthe convolvuli_CBS 124654 & КС343054.1 & КС343780.1 & КС344022.1 & КС343296.1 & КС343538.1 \\
\hline Diaporthe crataegi_CBS 114435 & КС343055.1 & КС343781.1 & КС344023.1 & КС343297.1 & КС343539.1 \\
\hline Diaporthe crotalariae_CBS 162.33 & КС343056.1 & КС343782.1 & KC344024.1 & КС343298.1 & КС343540.1 \\
\hline Diaporthe cuppatea_C̄BS 117499 & КС343057.1 & КС343783.1 & КС344025.1 & КС343299.1 & КС343541.1 \\
\hline Diaporthe cynaroidis_CBS 122676 & КС343058.1 & КС343784.1 & КС344026.1 & КС343300.1 & КС343542.1 \\
\hline Diaporthe decedens_CBS 109772 & КС343059.1 & КС343785.1 & КС344027.1 & КС343301.1 & КС343543.1 \\
\hline Diaporthe decedens_CBS 114281 & КС343060.1 & КС343786.1 & КС344028.1 & КС343302.1 & КС343544.1 \\
\hline Diaporthe detrusa_CBS 109770 & КС343061.1 & КС343787.1 & КС344029.1 & КС343303.1 & КС343545.1 \\
\hline Diaporthe detrusa_CBS 114652 & КС343062.1 & КС343788.1 & КС344030.1 & КС343304.1 & КС343546.1 \\
\hline Diaporthe elaeagni_CBS 504.72 & КС343064.1 & КС343790.1 & КС344032.1 & КС343306.1 & КС343548.1 \\
\hline Diaporthe endophytica_CBS 133811 & КС343065.1 & КС343791.1 & КС344033.1 & КС343307.1 & КС343549.1 \\
\hline Diaporthe endophytica_LGMF928 & КС343068.1 & КС343794.1 & КС344036.1 & КС343310.1 & КС343552.1 \\
\hline Diaporthe eres_CBS 439.82 & КС343090.1 & КС343816.1 & KC344058.1 & КС343332.1 & КС343574.1 \\
\hline Diaporthe eres_CBS 101742 & КС343073.1 & КС343799.1 & KC344041.1 & КС343315.1 & КС343557.1 \\
\hline Diaporthe eres_CBS 109767 & КС343075.1 & КС343801.1 & КС344043.1 & КС343317.1 & КС343559.1 \\
\hline Diaporthe cf. nobilis RG-2013_CBS 113470 & КС343146.1 & КС343872.1 & КС344114.1 & КС343388.1 & КС343630.1 \\
\hline Diaporthe cf. nobilis RG-2013_CBS 116953 & КС343147.1 & КС343873.1 & KC344115.1 & КС343389.1 & КС343631.1 \\
\hline
\end{tabular}


Table 2. Cont.

\begin{tabular}{|c|c|c|c|c|c|}
\hline Source & ITS & TEF1 & TUB & $C A L$ & HIS \\
\hline Diaporthe cf. nobilis RG-2013_CBS 200.39 & КС343151.1 & КС343877.1 & KC344119.1 & КС343393.1 & КС343635.1 \\
\hline Diaporthe eugeniae_CBS 444.82 & КС343098.1 & КС343824.1 & КС344066.1 & КС343340.1 & КС343582.1 \\
\hline Diaporthe fibrosa_CBS 109751 & КС343099.1 & КС343825.1 & КС344067.1 & КС343341.1 & КС343583.1 \\
\hline Diaporthe fibrosa_CBS 113830 & КС343100.1 & КС343826.1 & KC344068.1 & КС343342.1 & КС343584.1 \\
\hline Diaporthe foeniculacea_CBS 123208 & КС343104.1 & КС343830.1 & КС344072.1 & КС343346.1 & КС343588.1 \\
\hline Diaporthe foeniculacea_CBS 111553 & КС343101.1 & КС343827.1 & КС344069.1 & КС343349.1 & КС343585.1 \\
\hline Diaporthe foeniculacea_CBS 187.27 & КС343107.1 & КС343833.1 & KC344075.1 & КС343343.1 & КС343591.1 \\
\hline Diaporthe ganjae_CBS 180.91 & КС343112.1 & КС343838.1 & KC344080.1 & КС343354.1 & КС343596.1 \\
\hline Diaporthe gardeniae_CBS 288.56 & КС343113.1 & КС343839.1 & KC344081.1 & КС343355.1 & КС343597.1 \\
\hline Diaporthe helianthi_CBS 592.81 & КС343115.1 & КС343841.1 & KC344083.1 & КС343357.1 & КС343599.1 \\
\hline Diaporthe helianthi_CBS 344.94 & КС343114.1 & КС 343840.1 & КС344082.1 & КС343356.1 & КС343598.1 \\
\hline Diaporthe hickoriae_CBS 145.26 & КС343118.1 & КС343844.1 & КС344086.1 & КС343360.1 & КС343602.1 \\
\hline Diaporthe hongkongensis_CBS 115448 & КС343119.1 & КС343845.1 & КС344087.1 & КС343361.1 & КС343603.1 \\
\hline Diaporthe hordei_CBS 481.92 & КС343120.1 & КС343846.1 & КС344088.1 & КС343362.1 & КС343604.1 \\
\hline Diaporthe impulsa_CBS 114434 & КС 343121.1 & КС343847.1 & KC344089.1 & КС343363.1 & KC343605.1 \\
\hline Diaporthe impulsa_CBS 141.27 & КС343122.1 & КС343848.1 & КС344090.1 & КС343364.1 & КС343606.1 \\
\hline Diaporthe inconspicua_LGMF922 & КС343124.1 & КС343849.1 & KC344091.1 & КС343365.1 & КС343607.1 \\
\hline Diaporthe inconspicua_CBS 133813 & КС343123.1 & КС343850.1 & KC344092.1 & КС343366.1 & КС343608.1 \\
\hline Diaporthe infecunda_CBS 133812 & КС343126.1 & КС343852.1 & КС344094.1 & КС343368.1 & КС343610.1 \\
\hline Diaporthe infecunda_LGMF933 & КС343132.1 & КС343858.1 & КС344100.1 & КС343374.1 & КС343616.1 \\
\hline Diaporthe longispora_CBS 194.36 & КС343135.1 & КС343861.1 & KC344103.1 & КС343377.1 & КС343619.1 \\
\hline Diaporthe lusitanicae_CBS 123212 & КС343136.1 & КС343862.1 & КС344104.1 & КС343378.1 & КС343620.1 \\
\hline Diaporthe lusitanicae_CBS 123213 & КС343137.1 & КС343863.1 & КС344105.1 & КС343379.1 & КС343621.1 \\
\hline Diaporthe manihotia_CBS 505.76 & КС343138.1 & КС343864.1 & КС344106.1 & КС343380.1 & КС343622.1 \\
\hline Diaporthe mayteni_CBS 133185 & КС343139.1 & КС343865.1 & КС344107.1 & КС343381.1 & КС343623.1 \\
\hline Diaporthe megalospora_CBS 143.27 & КС343140.1 & КС343866.1 & КС344108.1 & КС343383.1 & КС343624.1 \\
\hline Diaporthe melonis_CBS 507.78 & КС343142.1 & КС343868.1 & KC344110.1 & КС343384.1 & КС343626.1 \\
\hline Diaporthe melonis_CBS 435.87 & КС343141.1 & КС343867.1 & KC344109.1 & КС343382.1 & КС343625.1 \\
\hline Diaporthe musigena_CBS 129519 & КС343143.1 & КС343869.1 & КС344111.1 & КС343385.1 & КС343627.1 \\
\hline Diaporthe neilliae_CBS 144.27 & КС343144.1 & КС343870.1 & KC344112.1 & КС343386.1 & КС343628.1 \\
\hline Diaporthe neoarctii_CBS 109490 & КС343145.1 & КС343871.1 & КС344113.1 & КС343387.1 & КС343629.1 \\
\hline Diaporthe nomurai_CBS 157.29 & КС343154.1 & KC343880.1 & KC344122.1 & КС343396.1 & КС343638.1 \\
\hline Diaporthe novem_CBS 127270 & КС343156.1 & КС343882.1 & КС344124.1 & КС343398.1 & КС343640.1 \\
\hline Diaporthe novem_CBS 354.71 & КС343158.1 & КС343884.1 & КС344126.1 & КС343400.1 & КС343642.1 \\
\hline Diaporthe oncostoma_CBS 109741 & КС343161.1 & КС343887.1 & КС344129.1 & КС343403.1 & КС343645.1 \\
\hline Diaporthe oncostoma_CBS 100454 & КС343160.1 & КС343886.1 & КС344128.1 & КС343402.1 & КС343644.1 \\
\hline Diaporthe oxe_CBS 133186 & КС343164.1 & КС343890.1 & КС344132.1 & КС343406.1 & КС343648.1 \\
\hline Diaporthe oxe_CBS 133187 & КС343165.1 & КС343891.1 & KC344133.1 & КС343407.1 & КС343649.1 \\
\hline Diaporthe padi var. padi_CBS 114200 & КС343169.1 & КС343895.1 & KC344137.1 & КС343411.1 & КС343653.1 \\
\hline Diaporthe padi var. padi_CBS 114649 & КС343170.1 & КС343896.1 & КС344138.1 & КС343412.1 & КС343654.1 \\
\hline Diaporthe paranensis_CBS 133184 & КС343171.1 & КС343897.1 & KC344139.1 & КС343413.1 & КС343655.1 \\
\hline Diaporthe perjuncta_CBS 109745 & КС343172.1 & КС343898.1 & КС344140.1 & КС343414.1 & КС343656.1 \\
\hline Diaporthe perseae_CBS 151.73 & КС343173.1 & КС343899.1 & КС344141.1 & КС343415.1 & КС343657.1 \\
\hline Diaporthe phaseolorum_CBS 116019 & КС343175.1 & КС343901.1 & KC344143.1 & КС343417.1 & КС343659.1 \\
\hline Diaporthe phaseolorum_CBS 116020 & КС343176.1 & КС343902.1 & КС344144.1 & КС343418.1 & КС343660.1 \\
\hline Diaporthe pseudomangiferae_CBS 101339 & КС343181.1 & КС343907.1 & КС344149.1 & КС343423.1 & КС343665.1 \\
\hline Diaporthe pseudomangiferae_CBS 388.89 & КС343182.1 & КС343908.1 & КС344150.1 & КС343424.1 & КС343666.1 \\
\hline Diaporthe pseudophoenicicola_CBS 462.69 & КС343184.1 & КС343910.1 & КС344152.1 & КС 343426.1 & КС343668.1 \\
\hline Diaporthe pseudophoenicicola_CBS 176.77 & КС343183.1 & КС343909.1 & КС344151.1 & КС343425.1 & КС343667.1 \\
\hline Diaporthe pustulata_CBS 109784 & КС343187.1 & КС343913.1 & КС344155.1 & КС343429.1 & КС343671.1 \\
\hline Diaporthe pustulata_CBS 109742 & КС343185.1 & КС343911.1 & КС344153.1 & КС343427.1 & КС343669.1 \\
\hline Diaporthe raonikayaporum_CBS 133182 & КС343188.1 & КС343914.1 & KC344156.1 & КС343430.1 & КС343672.1 \\
\hline Diaporthe rhoina_CBS 146.27 & КС343189.1 & КС343915.1 & КС344157.1 & КС343431.1 & КС343673.1 \\
\hline Diaporthe saccarata_CBS 116311 & КС343190.1 & КС343916.1 & КС344158.1 & КС343432.1 & КС343674.1 \\
\hline Diaporthe schini_CB- 133181 & КС343191.1 & КС343917.1 & KC344159.1 & КС343433.1 & КС343675.1 \\
\hline Diaporthe schini_LGMF910 & КС343192.1 & КС343918.1 & KC344160.1 & КС343434.1 & КС343676.1 \\
\hline Diaporthe sclerotioides_CBS 296.67 & КС343193.1 & КС343919.1 & КС344161.1 & КС343435.1 & КС343677.1 \\
\hline Diaporthe sclerotioides_CBS 710.76 & КС343194.1 & КС343920.1 & КС344162.1 & КС343436.1 & КС343678.1 \\
\hline Diaporthe scobina_CBS 251.38 & КС343195.1 & КС343921.1 & КС344163.1 & КС343437.1 & КС343679.1 \\
\hline Diaporthe sojae_CBS 100.87 & КС343196.1 & КС343922.1 & КС344164.1 & КС343438.1 & КС343680.1 \\
\hline Diaporthe longicolla isolate PL4 & HM347700.1 & HМ347685.1 & KС344167.1 & КС343441.1 & КС343683.1 \\
\hline Diaporthe sojae_CBS 116017 & КС343197.1 & КС343923.1 & КС344165.1 & КС343439.1 & КС343681.1 \\
\hline Diaporthe sojae_CBS 180.55 & КС343200.1 & КС343926.1 & КС344168.1 & КС343442.1 & КС343684.1 \\
\hline Diaporthe subordinaria_CBS 101711 & КС343213.1 & КС343938.1 & КС344180.1 & КС343454.1 & КС343696.1 \\
\hline Diaporthe subordinaria_CBS 464.90 & КС343214.1 & КС343939.1 & КС344181.1 & КС343455.1 & КС343697.1 \\
\hline
\end{tabular}


Table 2. Cont.

\begin{tabular}{|c|c|c|c|c|c|}
\hline Source & ITS & TEF1 & TUB & $C A L$ & HIS \\
\hline Diaporthe tecomae_CBS 100547 & КС343215.1 & KC343940.1 & КC 344102.1 & КС343456.1 & КC 345090.1 \\
\hline Diaporthe terebinthifolii_CBS 133180 & КС343216.1 & & & & \\
\hline Diaporthe terebinthifolii_LGMF907 & C343217.1 & КС343942.1 & КС344183.1 & КС343458.1 & KC 343700.1 \\
\hline Diaporthe toxica_CBS 534.93 & C343220.1 & КС343943.1 & КС344185.1 & КС343459.1 & КС343701.1 \\
\hline Diaporthe toxica_CBS 535.93 & C343221.1 & KC343946.1 & КС344188.1 & КС343462.1 & КС343704.1 \\
\hline Diaporthe vaccinii_CBS 160.32 & C 343228.1 & КС343947.1 & КС344189.1 & КС 343463.1 & КС 343705.1 \\
\hline Diaporthe vaccinii_CBS 122112 & C343224.1 & КС343954.1 & КС344196.1 & КС343470.1 & КС343712.1 \\
\hline Diaporthe vexans_CBS 127.14 & КС343229.1 & & & КС343466.1 & КС343708.1 \\
\hline Diaporthe rudis_CBS 1132 & & & & & \\
\hline Diap & & & & & \\
\hline Diapo & & KC34 & 1.1 & & 717.1 \\
\hline Diapo & & & & & 728.1 \\
\hline Diapo & & & & & 729.1 \\
\hline heveae 2 RG-201 & & & & & KC 343600.1 \\
\hline 1 RG-2013_CB & КС 3432 & КС343843.1 & КС344085.1 & КС343359.1 & KC343601.1 \\
\hline Diaporthe sp. 1 RG-2013_LGMF947 & КС343203.1 & КС343928.1 & КС344170.1 & КС343444.1 & КС343686.1 \\
\hline Diaporthe sp. 2 RG-2013_LGMF932 & КС343204.1 & КС343929.1 & КС344171.1 & КС343445.1 & KC343687.1 \\
\hline Diaporthe sp. 3 RG-2013_CBS 287.29 & КС343205.1 & КС343930.1 & КС344172.1 & КС343446.1 & КС343688.1 \\
\hline Diaporthe sp. 4 RG-2013_LGMF944 & КС343206.1 & КС343931.1 & КС344173.1 & КС343448.1 & КС343689.1 \\
\hline Diaporthe sp. 5 RG-2013_CBS 12557 & КС343207.1 & КС343932.1 & КС344174.1 & КС343447.1 & КС343690.1 \\
\hline Diaporthe sp. 6 RG-2013_CBS 115584 & КС343208.1 & КС343933.1 & КС344175.1 & КС343449.1 & КС343691.1 \\
\hline Diaporthe sp. 6 RG-201 & КС343209.1 & КС343934.1 & КС344176.1 & КС343450.1 & КС343692.1 \\
\hline Diaporthe & .1 & KC34 & $\mathrm{KC} 34$ & KC34 & KC343693.1 \\
\hline Diaporthe sp. 8 RG-2013_LGMF925 & & КС343936.1 & КС344178.1 & КС343452.1 & КС343694.1 \\
\hline Diaport & & & & & КС343695.1 \\
\hline Diaporthe stictica_CBS 370.54 & КС343212.1 & КС343730.1 & КС343972.1 & КС343246.1 & КС343488.1 \\
\hline
\end{tabular}

\subsection{Antifungal Activity Tests for Fungal VOCs}

The antifungal activity of the VOCs was determined by the methods previously described $[17,18,20]$. The four endophytic fungal strains of Diaporthe and targeted plant pathogenic microorganisms were paired opposite to each other in Petri plates containing PDA with a diameter of $90 \mathrm{~mm}$. The agar was divided into two halves by removing a $2 \mathrm{~cm}$ wide strip in the center. An endophytic test fungus was inoculated onto one half-moon of the agar and incubated at $25^{\circ} \mathrm{C}$ for five days for optimum production of volatile compounds before the antagonism bioassay. A test pathogen was inoculated onto the opposite half-moon part of the agar at the fifth day. The plates were then wrapped with parafilm and incubated at $25^{\circ} \mathrm{C}$ in dark for $72 \mathrm{~h}$. Growth of filamentous pathogenic fungi were quantitatively assessed after $24 \mathrm{~h}, 48 \mathrm{~h}$, and $72 \mathrm{~h}$ based on multiple measurements of growth relative to controls, as described previously $[17,18]$. The colony diameter was measured in an average of four diameters on hours 24,48 , and $72 \mathrm{~h}$, disregarding the initial inoculum size. Percentage of growth inhibition was calculated as the formula: $|(a-b / b)| \times 100, a=$ mycelial colony diameter in control plate; $b=$ mycelial colony diameter in the antagonism treatment plate. Statistical significance $(p<0.01)$ was evaluated by analysis of variance (ANOVA) followed by the Tukey $5 \%$ test. Antifungal activity of VOCs was tested against the plant pathogenic fungi Alternaria alternata, Botryosphaeria dothidea, Botrytis cinerea, Cercospora sp., Colletotrichum gloeosporioides, Fusarium graminearum, Sphaeropsis sapinea, and Valsa sordida, in addition to the oomycete Phytophthora cinnamomi. All tests were made in quintuplicate. Control cultures were obtained by growing each plant pathogen alone, under the same conditions.

\subsection{Qualitative Analyses on Volatiles of the Four Endophytic Cultures}

VOCs in the air space above the endophytic fungal colonies grown for five days at $25 \pm 2{ }^{\circ} \mathrm{C}$ on PDA were analyzed using the solid phase microextraction (SPME) fiber technique according to previously described protocols $[17,18,20]$. Control PDA Petri plates not inoculated with the strain was used to subtract compounds contributed by the medium. All treatments and checks were done in triplicate. A fiber syringe of 50/30 divinylbenzene/carboxen on polydimethylsiloxane (Supelco, Bellefonte, PA, USA) was conditioned for $40 \mathrm{~min}$ at $200{ }^{\circ} \mathrm{C}$, exposed to the vapor phase inside Petri 
during $40 \mathrm{~min}$ through a small hole $(0.5 \mathrm{~mm}$ in diameter) drilled on the sides of the Petri plate. The fiber was directly inserted into the TRACE DSQ inlet (Thermo Electron Corporation, Beverly, MA, USA), at $200{ }^{\circ} \mathrm{C}$, splitless mode. The desorption time was $40 \mathrm{~s}$ and the desorbed compounds were separated on a $30.0 \mathrm{~m} \times 0.25 \mathrm{~mm} \times 0.25 \mu \mathrm{m}$, HP-5MS capillary column, using the following GC oven temperature program: $2 \mathrm{~min}$ at $35^{\circ} \mathrm{C}$ up to $220^{\circ} \mathrm{C}$ at $7{ }^{\circ} \mathrm{C} / \mathrm{min}$. Helium was used as the carrier gas at a flow rate of $1 \mathrm{~mL} / \mathrm{min}$. The electronic ionization energy was $70 \mathrm{eV}$ and the mass range scanned was 41-560 uma. The scan rate was $5 \mathrm{spec} / \mathrm{s}$. Transfer line and ionization chamber temperatures were $250^{\circ} \mathrm{C}$ and $200^{\circ} \mathrm{C}$ respectively. Tentative identification of the volatile compounds produced by the four endophytic Diaporthe fungi was made via library comparison using the NIST database and all chemical compounds were described in this report following the NIST database chemical identity. Tentative compound identity was based on at least a 70\% quality match with the NIST database information for each compound. Data acquisition and data processing were performed with the Hewlett Packard ChemStation software system (Version 2.0, Scientific Instrument Services, Inc., Ringoes, NJ, USA). Relative amounts of individual components of the treatments were determined and expressed as percentages of the peak area within the total peak area and as an average of the three replicates.

\section{Results}

\subsection{The Identification on the Four Endophytic Isolates within the Diaporthe Genus}

Each of the four isolates falling within the genus Diaporthe were further defined using molecular analyses as they appeared different, morphologically (Figure 1). For instance, strain FPYF3053 had compact mycelia with crenate margins, these colonies developed a brownish yellow pigmentation in the center on the underside having a growth rate of $18.3 \mathrm{~mm}_{\text {day }}{ }^{-1}$ (Figure 1a). On the other hand, strain FPYF3054 had aerial mycelium forming concentric rings with grey and dark pigmentation at the center showing a growth rate of $30.97 \mathrm{~mm} \mathrm{day}^{-1}$ (Figure 1b). Strain FPYF3055 had vigorously-growing aerial hyphae near the margin, but loose hyphae scattered inside with aging, with a growth rate of $23 \mathrm{~mm} \mathrm{day}^{-1}$ (Figure 1c). Finally, strain FPYF3056 had a compact mycelium with a crenate margin, but no pigmentation with a growth rate of $21.7 \mathrm{~mm} \mathrm{day}^{-1}$ (Figure 1d).

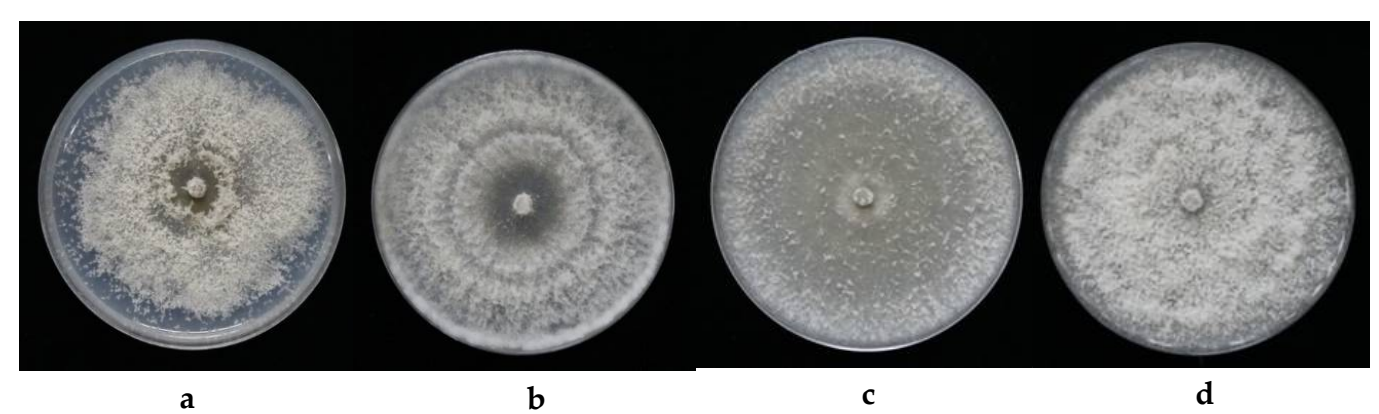

Figure 1. The colony cultures for the four endophytic Diaporthe fungi and their plant host. (a) FPYF3053; (b) FPYF3054; (c) FPYF3055; and (d) FPYF3056.

A combined alignment of five loci ITS, TUB, TEF1, HIS, and CAL was used for ML and MP phylogenic analyses. Based on the multi-locus phylogeny (Figure 2), the four endophytic Diaporthe strains could not be placed in one species only because they are distinct from each other and from all reference species listed (Table 2, Figure 2). Strains FPYF3055 and FPYF3056 were clustered by giving a high bootstrap support (BS = 82) from MP inference (Figure S1) while both separated from each other in ML inference (Figure S2). The reference sequences used to construct the phylogenetic tree were listed in Table 2 with their Genbank accession numbers. The alignment was uploaded in Treebase assigned with SI 22757. 


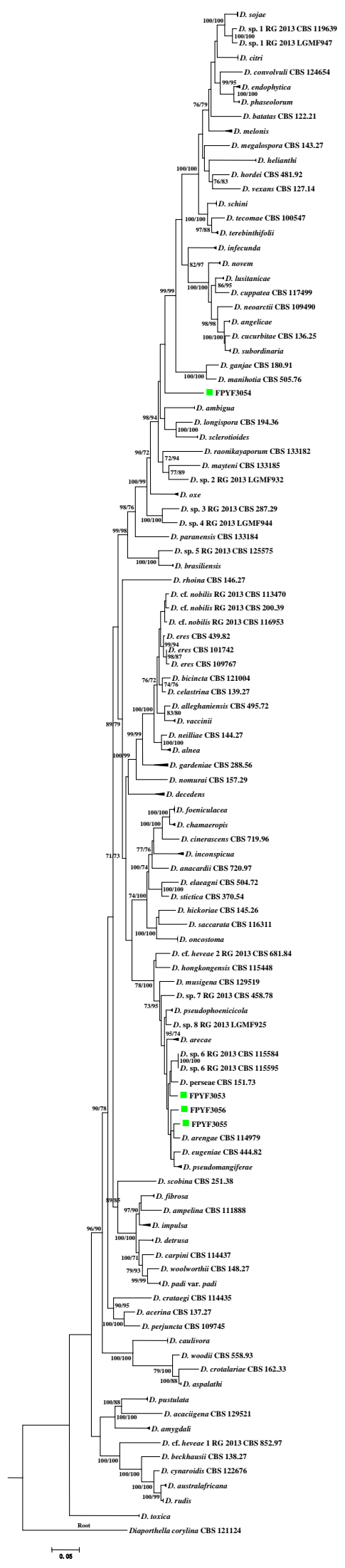

Figure 2. Phylogenetic tree based on combinedITS, CAL, TEF1, HIS, and TUB sequence alignment generated from a maximum parsimony and maximum likelihood analyses. Values near the branches represent parsimony/likelihood bootstrap support values $(>70 \%)$, respectively. The tree is rooted with Diaporthella corylina. The four endophytic isolates were each named with strain ID marked green box. Compressed branches were used for saving space. The complete phylogenetic trees of MP and ML can be found in Figures S1 and S2, respectively. 


\subsection{The VOCs' Bioactivities of the Four Diaporthe Strains against Plant Fungal Pathogens}

All of the four strains were observed to inhibit the growth of nine selected fungal pathogens by producing volatile compounds in the PDA medium (Table 3). The nine pathogens, Alternaria alternata, Botryosphaeria dothidea, Botrytis cinerea, Cercospora asparagi, Colletotrichum gloeosporioides, Fusarium graminearum, Phytophthora cinnamomi, Sphaeropsis sapinea, and Valsa sordida, are important causal agents to major trees, such as poplars and pines, or agricultural crops in China and elsewhere. All FPYF strains showed different inhibitory activities along the measurements, an exception was observed for the case of strain FPYF3053, which promoted the growth of Phytophthora cinnamomi (Table 3). Furthermore, all selected pathogens, except $V$. sordid, achieved obvious growth inhibition over around $10 \%$ during the testing period. After $24 \mathrm{~h}$, B. cinerea was the most sensitive to VOCs emitted by all endophytic strains, reaching percent inhibitions of more than $55 \%$ when dual cultured with each strain. B. dothidea and A. alternata were highly sensitive to VOCs of all the endophytic strains, getting percent inhibitions of more than $30 \%$ with an exception to $28 \%$ of A. alternata in VOCs of the strain FPYF3053. $V$. sordida had the least sensitive or insensitive performance in VOCs from all the strains, showing percent inhibitions around 3\% when dual cultured with FPYF3056. The inhibitive intensity of FPYF strains' VOCs on growth of pathogens decreased in times to most duel cultures. The maximum drop of the intensity was by $31 \%$ in percent inhibition on the pathogen B. cinerea duel culturing with strain FPYF3056. The obvious increase in intensity occurred in the pathogen F. graminearum duel culturing with FPYF3055 and FPYF3056, increasing by around 10\% during $72 \mathrm{~h}$. Some pathogens grew fast without percent inhibition records after $24 \mathrm{~h}$ (V. sordida) or $72 \mathrm{~h}$ (B. dothidea and F. graminearum).

Table 3. Growth inhibition percentage of plant pathogens by VOC bioassays of four Diaporthe strains. Percent of inhibition is shown as the means of four measurements of diameters with standard deviation $(n=4)$.

\begin{tabular}{|c|c|c|c|c|c|c|c|c|c|}
\hline \multirow[b]{2}{*}{ Pathogen } & \multirow[b]{2}{*}{ Day } & \multicolumn{2}{|c|}{ FPYF3053 } & \multicolumn{2}{|c|}{ FPYF3054 } & \multicolumn{2}{|c|}{ FPYF3055 } & \multicolumn{2}{|c|}{ FPYF3056 } \\
\hline & & $\begin{array}{l}\text { Percentage } \\
\text { Inhibition }\end{array}$ & $p$-Value & $\begin{array}{l}\text { Percentage } \\
\text { Inhibition }\end{array}$ & $p$-Value & $\begin{array}{l}\text { Percentage } \\
\text { Inhibition }\end{array}$ & $p$-Value & $\begin{array}{l}\text { Percentage } \\
\text { Inhibition }\end{array}$ & $p$-Value \\
\hline \multirow{3}{*}{$\begin{array}{l}\text { Alternaria } \\
\text { alternata }\end{array}$} & $24 \mathrm{~h}$ & $28.77 \pm 2.26$ & 0.0003 & $41.41 \pm 1.65$ & 0.0001 & $37.68 \pm 5.6$ & 0.0078 & $34.51 \pm 2.03$ & 0.0002 \\
\hline & $48 \mathrm{~h}$ & $22.42 \pm 2.34$ & 0.0003 & $30.19 \pm 1.56$ & 0.0009 & $30.25 \pm 5.12$ & 0.0113 & $26.50 \pm 3.42$ & 0.0006 \\
\hline & $72 \mathrm{~h}$ & $15.25 \pm 2.59$ & 0.0019 & $23.43 \pm 2.27$ & 0.0039 & $22 \pm 4.03$ & 0.0148 & $16.34 \pm 2.36$ & 0.0010 \\
\hline \multirow{3}{*}{$\begin{array}{l}\text { Botryosphaeria } \\
\text { dothidea }\end{array}$} & $24 \mathrm{~h}$ & $46.3 \pm 4.30$ & 0.0030 & $50.17 \pm 2.43$ & 0.0006 & $43.74 \pm 2.15$ & 0.0000 & $37.88 \pm 3.80$ & 0.0002 \\
\hline & $48 \mathrm{~h}$ & $45.28 \pm 2.63$ & 0.0000 & $45.14 \pm 2.35$ & 0.0000 & $42.78 \pm 0.43$ & 0.0000 & $38.99 \pm 0.98$ & 0.0000 \\
\hline & $72 \mathrm{~h}$ & \multicolumn{8}{|c|}{$\mathrm{NE}^{*}$} \\
\hline \multirow{3}{*}{$\begin{array}{l}\text { Botrytis } \\
\text { cinerea }\end{array}$} & $24 \mathrm{~h}$ & $64.47 \pm 1.05$ & 0.0000 & $55.26 \pm 4.82$ & 0.0000 & $60.72 \pm 1.91$ & 0.0001 & $55.26 \pm 4.71$ & 0.0000 \\
\hline & $48 \mathrm{~h}$ & $50.42 \pm 1.79$ & 0.0000 & $35.02 \pm 1.22$ & 0.0000 & $39.44 \pm 3.70$ & 0.0000 & $32.41 \pm 3.75$ & 0.0003 \\
\hline & $72 \mathrm{~h}$ & $36.55 \pm 2.81$ & 0.0000 & $24.27 \pm 3.08$ & 0.0001 & $30.10 \pm 3.54$ & 0.0005 & $24.25 \pm 4.62$ & 0.0025 \\
\hline \multirow{3}{*}{$\begin{array}{c}\text { Cercospora } \\
\text { asparagi }\end{array}$} & $24 \mathrm{~h}$ & $31.46 \pm 4.11$ & 0.0003 & $22.64 \pm 2.86$ & 0.0074 & $23.21 \pm 4.54$ & 0.0202 & $18.57 \pm 5.01$ & 0.0086 \\
\hline & $48 \mathrm{~h}$ & $33.81 \pm 2.97$ & 0.0000 & $24.32 \pm 2.21$ & 0.0008 & $22.02 \pm 2.96$ & 0.0000 & $16.34 \pm 1.53$ & 0.0000 \\
\hline & $72 \mathrm{~h}$ & $23.32 \pm 2.17$ & 0.0007 & $19.09 \pm 2.73$ & 0.0031 & $11.94 \pm 3.54$ & 0.0083 & $4.56 \pm 0.85$ & 0.0032 \\
\hline \multirow{3}{*}{$\begin{array}{l}\text { Colletotrichum } \\
\text { gloeosporioides }\end{array}$} & $24 \mathrm{~h}$ & $26.83 \pm 4.78$ & 0.0153 & $9.75 \pm 2.33$ & 0.0009 & $10.68 \pm 1.14$ & 0.0001 & $10.74 \pm 2.38$ & 0.0229 \\
\hline & $48 \mathrm{~h}$ & $20.94 \pm 3.33$ & 0.0051 & $11.76 \pm 2.35$ & 0.0006 & $8.91 \pm 1.24$ & 0.0001 & $9.78 \pm 2.36$ & 0.0017 \\
\hline & $72 \mathrm{~h}$ & $20.68 \pm 1.56$ & 0.0024 & $9.39 \pm 2.78$ & 0.0023 & $6.29 \pm 0.80$ & 0.0001 & $6.82 \pm 2.01$ & 0.0388 \\
\hline \multirow{3}{*}{$\begin{array}{l}\text { Fusarium } \\
\text { graminearum }\end{array}$} & $24 \mathrm{~h}$ & $25.68 \pm 1.13$ & 0.0031 & $14.68 \pm 2.05$ & 0.0147 & $20.45 \pm 3.62$ & 0.0046 & $12.96 \pm 1.42$ & 0.0103 \\
\hline & $48 \mathrm{~h}$ & $29.99 \pm 5.29$ & 0.0086 & $12.9 \pm 4.50$ & 0.0284 & $31.12 \pm 3.57$ & 0.0203 & $21.59 \pm 4.57$ & 0.0425 \\
\hline & $72 \mathrm{~h}$ & \multicolumn{8}{|c|}{ NE } \\
\hline \multirow{3}{*}{$\begin{array}{l}\text { Phytophthora } \\
\text { cinnamomi }\end{array}$} & $24 \mathrm{~h}$ & $-5.01 \pm 1.14^{* *}$ & 0.0029 & $19.21 \pm 4.54$ & 0.0036 & $31.02 \pm 2.58$ & 0.0001 & $8.38 \pm 3.10$ & 0.0154 \\
\hline & $48 \mathrm{~h}$ & $-15.65 \pm 6.36$ & 0.0186 & $12.19 \pm 3.30$ & 0.0500 & $25.21 \pm 4.29$ & 0.0050 & $11.32 \pm 4.22$ & 0.0302 \\
\hline & $72 \mathrm{~h}$ & $-19.70 \pm 4.19$ & 0.0153 & $11.91 \pm 2.12$ & 0.0209 & $21.03 \pm 2.80$ & 0.0031 & $8.94 \pm 2.03$ & 0.0013 \\
\hline \multirow{3}{*}{$\begin{array}{c}\text { Sphaeropsis } \\
\text { sapinea }\end{array}$} & $24 \mathrm{~h}$ & $23.39 \pm 4.25$ & 0.0147 & $22.69 \pm 5.23$ & 0.0239 & $21.84 \pm 7.61$ & 0.0491 & $7.41 \pm 2.68$ & 0.0364 \\
\hline & $48 \mathrm{~h}$ & $20.93 \pm 1.04$ & 0.0009 & $23.85 \pm 1.68$ & 0.0023 & $18.33 \pm 5.22$ & 0.0367 & $9.53 \pm 0.60$ & 0.0024 \\
\hline & $72 \mathrm{~h}$ & \multicolumn{8}{|c|}{ NE } \\
\hline \multirow{3}{*}{ Valsa sordida } & $24 \mathrm{~h}$ & $5.96 \pm 1.61$ & 0.0115 & $9.73 \pm 2.79$ & 0.0014 & $5.14 \pm 1.02$ & 0.0153 & $3.15 \pm 1.00$ & 0.0177 \\
\hline & $48 \mathrm{~h}$ & \multirow{2}{*}{\multicolumn{8}{|c|}{$\begin{array}{l}\mathrm{NE} \\
\mathrm{NE}\end{array}$}} \\
\hline & $72 \mathrm{~h}$ & & & & & & & & \\
\hline
\end{tabular}

* No data. ${ }^{* *}$ Negative values mean growth stimulation. 
Table 4. Chemical composition of volatiles obtained from mycelial cultures of the four endophytic Diaporthe fungi using solid-phase microextraction (SPME).

\begin{tabular}{|c|c|c|c|c|c|c|c|c|c|c|}
\hline \multirow{2}{*}{$\begin{array}{l}\text { Retention } \\
\text { Time (min) }\end{array}$} & \multirow{2}{*}{$\begin{array}{l}\text { Molecular } \\
\text { Weight }\end{array}$} & \multirow{2}{*}{ Compound } & \multicolumn{4}{|c|}{ Quality (\%) $^{\mathrm{a}}$} & \multicolumn{4}{|c|}{ Abundance (Relative) ${ }^{\mathbf{b}}$} \\
\hline & & & FPYF3053 & FPYF3054 & FPYF3055 & FPYF3056 & FPYF3053 & FPYF3054 & FPYF3055 & FPYF3056 \\
\hline 6.17 & 106 & Ethylbenzene & & 91.8 & 75.5 & 77.9 & & 0.42 & 0.80 & 0.92 \\
\hline 7.67 & 136 & $\alpha$-Thujene & 91.9 & & 89.3 & 89.8 & 30.57 & & 37.10 & 36.19 \\
\hline 9.88 & 136 & 1,3-Cyclohexadiene, 1-methyl-4-(1-methylethyl)- & 84.7 & & 80.2 & 81.2 & 6.26 & & 5.92 & 1.87 \\
\hline 9.89 & 136 & 2-Carene & 86 & & & 84.9 & 1.80 & & & 6.20 \\
\hline 10.21 & 136 & $\alpha$-Phellandrene & & 74.9 & 78 & & & 0.74 & 5.15 & \\
\hline 10.22 & 136 & $\beta$-Phellandrene & 88.4 & 90.9 & 75.2 & 87.7 & 12.55 & 56.07 & 2.35 & 18.70 \\
\hline 10.92 & 136 & $\gamma$-Terpinene & 89.4 & & 85.6 & 88.7 & 21.15 & & 16.82 & 19.21 \\
\hline 11.63 & 136 & Cyclohexene, 1-methyl-4-(1-methylethylidene)- & & & 81.1 & & & & 1.66 & \\
\hline 11.89 & 154 & 2-Cyclohexen-1-ol, 1-methyl-4-(1-methylethyl)- & 81 & & & & 0.65 & & & \\
\hline 12.29 & 152 & Unknown & 63.4 & & 68.2 & & 0.29 & & 1.24 & \\
\hline 12.3 & 152 & Thujone & & & & 71.5 & & & & 0.65 \\
\hline 13.21 & 154 & 1-Menthone & & 90.4 & & & & 27.91 & & \\
\hline 13.68 & 156 & Cyclohexanol, 5-methyl-2-(1-methylethyl)- & & 87.6 & & & & 10.29 & & \\
\hline 13.76 & 154 & 3-Cyclohexen-1-ol, 4-methyl-1-(1-methylethyl)-, (R)- & 88.5 & & 89.7 & 85.6 & 5.53 & & 22.38 & 5.88 \\
\hline 13.91 & 208 & 2,4,4-Trimethyl-3-(3-methylbutyl)cyclohex-2-enone & & 70.1 & & & & 0.44 & & \\
\hline 14.12 & 352 & Unknown & 66.3 & & & & 0.28 & & & \\
\hline 14.13 & 240 & Unknown & & & & 64.4 & & & & 0.59 \\
\hline 14.14 & 170 & Unknown & & & 64.9 & & & & 1.35 & \\
\hline 17.42 & 388 & Unknown & & & & 60.9 & & & & 0.31 \\
\hline 18.41 & 188 & Biphenylene, 1,2,3,6,7,8,8a,8b-octahydro-4,5-dimethyl- & 79 & 73.9 & 68.5 & 72.2 & 7.05 & 1.62 & 2.06 & 6.81 \\
\hline 18.92 & 204 & Caryophyllene & 73.6 & & & & 0.46 & & & \\
\hline 19.11 & 204 & Unknown & 69.7 & & & & 0.31 & & & \\
\hline 19.74 & 204 & Patchoulene & 76.8 & & & & 0.45 & & & \\
\hline 20.01 & 222 & Unknown & & & & 63.1 & & & & 0.41 \\
\hline 20.13 & 204 & Cedrene & 78.2 & & & & 1.11 & & & \\
\hline 20.46 & 204 & $\alpha$-Muurolene & 92.2 & 81.1 & 81 & 81.6 & 11.54 & 2.51 & 3.17 & 2.26 \\
\hline
\end{tabular}

Notes: Data are averages of two cultures grown on the same medium with subtracting those from the control PDA plat identical to that which is listed on the table based on the NIST database. Compounds assigned as unknown with lower than $70 \%$ quality match. ${ }^{\mathrm{b}}$ The abundance figure presents the percentage amount of each compound in total area relative to all listed compounds detected for one strain. 


\subsection{The Qualification on VOCs of the Four Endophytic Diaporthe Strains}

Each of the Diaporthe isolates showed a unique VOC profile as measured by SPME (Table 4). Nineteen VOC components from the four fungi were identified and seven compounds were unidentified according our set standard of a 70\% quality match with the GC-MS. Generally, the terpenoids were the major components in the VOCs of each strain. The main terpenes included $\alpha$-thujene, $\beta$-phellandrene, $\gamma$-terpinene, l-menthone, cyclohexanol, 5-methyl-2-(1-methylethyl)-, $\alpha$-muurolene. The amounts of each component of these monoterpenes had a relative area over $10 \%$ of the total of its VOCs. There also existed other minor terpenoids at very low amounts, including carene, $\alpha$-phellandrene, thujone, caryophyllene, patchoulene, etc. Two monoterpenes, $\beta$-phellandrene and $\alpha$-muurolene, and a chemical biphenylene,1,2,3,6,7,8,8a,8b-octahydro-4,5-dimethyl, which were detected in VOCs of all four strains. Four chemicals were common to VOCs from FPYF3053, FPYF3055, and FPYF3056, including $\alpha$-thujene, 1,3-cyclohexadiene, 1-methyl-4-(1-methylethyl)-, $\gamma$-terpinene and 3-cyclohexen-1-ol, and 4-methyl-1-(1-methylethyl)-,(R)-. However, each strain produced a unique mixture of volatile organic compounds. The strain FPYF3053 produced 15 volatile compounds with three prominent components, $\alpha$-thujene, $\beta$-phellandrene, and $\alpha$-muurolene. FPYF3054 was able to synthesize eight compounds with three prominent components of $\beta$-phellandrene, 1-menthone, and cyclohexanol,5-methyl-2-(1-methylethyl)- in VOC mixtures. Strains FPYF3055 and 3056 generated relatively close chemical compositions in amount and quality of VOCs compared to FPYF3053 and FPYF3054. However, FPYF3055 had three prominent components, $\alpha$-thujene, $\gamma$-terpinene, and 3-cyclohexen-1-ol,4-methyl-1-(1-methylethyl)-,(R)-, in 12 compounds of the VOCs, while FPYF3056 had three prominent components-namely $\alpha$-thujene $\beta$-phellandrene, and $\gamma$-terpinene —of 13 compounds in its VOCs.

\section{Discussion}

\subsection{Endophytic Diaporthe spp. from Catharanthus roseus}

Four isolates of endophytes in the genus Diaporthe were obtained from the medicinal plant Catharanthus roseus growing in a conservation area of Southern China. In order to best distinguish these individual organisms they were subjected to a combined analysis of five-loci alignment of TEF1-TUB-CAL-HIS-ITS which gave a more robust isolate identification [23]. Adding our four endophytic isolates did not affect the congruency in each locus, partition homogeneity for the combination and the best evolutionary model for the five-locus concatenated alignment reported. Diaporthe fungi are one of the most common endophytic fungal communites found in plants [11]. However, the previous work on endophytic fungi from C. roseus $[7,8,32-42]$ did not record strains of the Diaporthe genus. Alternaria alternata was determined as the dominant endophytic species in leaf tissue of C. roseus along with associated fungi from the following genera, Aspergillus, Fusarium, Penicillium, and Helminthosporium [33]. In addition the endophytes of root tissue appeared including Colletotrichum sp., Macrophomina phaseolina, Nigrospora sphaerica, and Fusarium solani [7]. Other isolated endophytic fungi from this plant included Colletotrichum truncatum, Drechsclera sp., Cladosporium sp., and Myrothecium sp. [43]. To our four Diaporthe strains, no reproductive structures were obtained in the employed conditions. They were designated Diaporthe sp. strains (FPYF3053-3056) without spore characterization strictly using phylogenetic analysis. The strains seemed not to share a close phylogenetic relationship to any other species based on the five-locus alignment study (Figure 2, [12,23,26]). The robust inference on the strains will take place when fruits bodies appear combined with full species phylogeny in the genus Diaporthe.

\subsection{VOCs Antifungal Effects of Endophytic Diaporthe spp. from Catharanthus roseus}

Compounds extracted from Catharanthus roseus [4,5] and extracts from some endophytes of this plant $[10,44]$ have been shown to have antimicrobial bioactivities to some human microbial pathogens and plant fungal pathogens, including Staphylococcus aureus, Pseudomonas aeruginosa, Bacillus subtilis, 
Escherichia coli, Aspergillus fumigatus, Candida albicans, etc. However, the VOCs or essential oils from Catharanthus roseus in the literature is scarce results on antimicrobial activities [45,46]. The previous work on the other endophytic fungi of this host plant did not consider that VOCs of the endophyte may have antimicrobial activities [7,8,32-42]. However, this work shows that VOCs produced by four endophytic Diaporthe fungi from the plant are able to functionally inhibit the growth of a number of specifically-targeted fungal pathogens (Table 3).

In the past there have been three endophytic Diaporthe strains recorded with their VOCs $[18,19,47]$. Two of them were reported to be inhibitory to plant pathogens $[18,19]$. One strain PR4 was isolated from a medicinal plant growing in Kashimir, Himalayas [19]; the other strain EC-4 was isolated from Odontoglossum sp. in Northern Ecuador [18]. With our four strains, the volatile compounds from endophytic Diaporthe fungi varied in degrees of inhibition against selected pathogenic fungi and test timings depending on the endophytic strain (Tables 3 and 5). However, the maximal inhibition of fungal growth of Diaporthe was from strain PR4, which reduced growth of Rhizoctonia solani by $100 \%$. FPYF strains' and EC-4 VOCs also appeared effective in the inhibition of growth of Botrytis cinerea by more than $30 \%$ with a maximal of $50.42 \pm 1.8 \%$. During the test course of $72 \mathrm{~h}$, to most cases, FPYF strains' VOCs showed strong bioactivities in the first day and then decreased inhibition on the pathogens in following two days (Table 3). PR4 VOCs were effective in reducing radial growth of Pythium ultimatum by $13.3 \%$; EC-4 VOCs were effective in reducing radial growth of Pythium ultimatum, Phytophthora cinnamomi, and Phytophthora palmivora by $59.1 \pm 0.9 \%, 42.0 \pm 0.5 \%$, and $5.6 \pm 0.5 \%$, respectively. FPYF3054-3056's VOCs were effective against Phytophthora cinnamomi in a range of $25.21 \pm 4.3 \sim 11.32 \pm 4.2 \%$. The alcohol compounds such as 1-propanol,2-methyl- and 1-butanol,3-methyl- might made the oomycete P. cinnamomi more sensitive to EC-4's VOCs [18], which were lack in VOCs of all FPYF strains (Table 4). The two alcohol compounds had antimicrobial activities in VOCs of endophytic Phomopsis sp. strain EC-4 [18]. The sensitivity of the pathogen F. graminearum to VOCs from Diaprothe spp. might be analogous even though the VOCs components were not similar among Diaprothe strains. Two Diaporthe strains FPYF3053, 3055 (Table 2) and Diaporthe strain PR4 [19] had percent inhibition of $F$. graminearum growth of around $30 \%$ under their VOCs bioactivities. However, only beta-phellandrene was a common compound found in VOCs among them (Table 4, [19]). Contrast to cytochalasins as a predominantly common component in soluble secondary metabolites of Diaporthe strains [16], the genus-specific or predominant conserved components of fungal VOCs of genus Diaporthe should be proposed to illustrate further. The experimental data suggests that the VOCs of FPYF strains are both biologically active and biologically selective. Finally, isolate FPYF3053 were showed no effective inhibition of Phytophthora cinnamomi growth. In this study, we attempt to understand the VOCs inhibitory impacts from the endophytic Diaporthe strains without consideration of interaction between the strains and pathogenes. Future research is proposed to investigate the dual interaction in the VOCs' levels and other molecules between fungal interactions [48].

The headspace analyses of the four Diaporthe strains in potato dextrose medium revealed that three monoterpenes- $\beta$-phellandrene, biphenylene,1,2,3,6,7,8,8a,8b-octahydro-4,5-dimethyl and $\alpha$-muurolene-seemed to be characteristic compounds of endophytic Diaporthe strains endophytic to Catharathus roseus. However, among all monoterpenes mentioned above, only 1-menthone can be found in volatile compounds of Catharathus roseus flowers, the essential oil of which is high in limonene and other monoterpenes $[45,46]$. Menthol and $\beta$-phellandrene were also found in VOCs of Diaporthe strain PR4 with very low relative amounts of less than 1.0\% [19]. No chemicals were shared in VOCs between our FPYF strains and Phomopsis strain EC-4 (Table 4, [18]). Therefore, the antifungal VOCs from the four endophytic Diaporthe Chinese strains possesses unique VOC compositions compared with known Diaporthe VOCs. Although many fungi were reported to produce many terpene compounds in their VOCs [49], our Diaporthe fungi maybe of some interest as a source of some other monoterpenes, which often only have been thought to originate from specific plants. For instance, essential oils from many plants containing more or less such monoterpenes as $\alpha$-thujene, $\beta$-phellandrene [50-52], $\gamma$-terpinene [53,54], 1-menthone [55,56], cyclohexanol, $\alpha$-muurolene, thujone, and caryophyllene have 
some antifungal activities. For example, $\gamma$-terpinene, singly or in mixtures with sabinene in oil from coastal redwood leaves, has strong antifungal activity on some endophytic fungi [53]. Therefore, it could be rational to infer the terpenes in FPYF strains synergistically played a main role in their inhibition pathogenic fungi growths. In addition, the high content of monoterpenes in the Diaporthe VOCs does have potential for the biofuel industry $[18,20,57]$.

Table 5. Comparison VOCs' inhibitive effect among Diaporthe strains.

\begin{tabular}{|c|c|c|c|}
\hline \multirow[b]{2}{*}{ Pathogens } & \multicolumn{3}{|c|}{ Percent Growth Inhibition } \\
\hline & $\begin{array}{l}\text { Phomopsis sp. } \\
\text { EC-4 [17] * }\end{array}$ & $\begin{array}{c}\text { Diaporthe Strain } \\
\text { PR4 [18] }\end{array}$ & FPYF3053-3056 ** \\
\hline Aspergillus flavus & /*** & 34.6 & / \\
\hline Aspergillus fumigatus & $57.0 \pm 0.5$ & / & / \\
\hline Alternaria alternata & / & / & $30.25 \pm 5.1 \sim 22.42 \pm 2.3$ \\
\hline Botryosphaeria dothidea & / & / & $45.14 \pm 2.4 \sim 25.28 \pm 2.6$ \\
\hline Botrytis cinerea & $37.8 \pm 0.5$ & / & $50.42 \pm 1.8 \sim 32.41 \pm 3.8$ \\
\hline Ceratocystis fimbriata & / & 0.0 & / \\
\hline Ceratocystis ulmi & $11.1 \pm 1.5$ & / & / \\
\hline Cercospora asparagi & / & / & $33.81 \pm 2.97 \sim 16.34 \pm 1.5$ \\
\hline Cercospora beticola & $19.5 \pm 0.5$ & / & / \\
\hline Colletotrichum sp. & / & / & $20.94 \pm 3.3 \sim 8.91 \pm 2.4$ \\
\hline Colletotrichum lagenarium & 0.0 & / & / \\
\hline Fusarium oxysporum & / & 34.6 & $31.12 \pm 3.6 \sim 12.9 \pm 4.5$ \\
\hline Fusarium solani & $43.2 \pm 0.00$ & 16.6 & 1 \\
\hline Geotrichum candidum, & $45.3 \pm 0.5$ & 57.0 & / \\
\hline Trichoderma viride & 0.0 & / & / \\
\hline Rhizoctonia solani & $53.0 \pm 1.0$ & 100 & / \\
\hline Sphaerospsis sapinea & / & / & $23.85 \pm 1.7 \sim 9.53 \pm 0.6$ \\
\hline Sclerotinia sclerotiorum & $70.7 \pm 1.1$ & / & / \\
\hline Valsa sordida & / & / & $9.73 \pm 2.8 \sim 3.15 \pm 1.00$ \\
\hline Verticillium dahliae & $19.4 \pm 0.0$ & 0.0 & / \\
\hline Pythium ultimatum & $59.1 \pm 0.9$ & 13.3 & / \\
\hline Phytophthora cinnamomi & $42.0 \pm 0.5$ & / & $-19.70 \pm 4.19 \sim-5.01 \pm 1.14,25.21 \pm 4.3 \sim 11.32 \pm 4.2$ \\
\hline Phytophthora palmivora & $5.6 \pm 0.5$ & / & / \\
\hline
\end{tabular}

${ }^{*}$ Data reference, ${ }^{* *}$ the values listed as range for the four strains during $72 \mathrm{~h},{ }^{* * *}$ no data.

Supplementary Materials: The following are available online at http:/ / www.mdpi.com/2309-608X/4/2/65/ s1. Figure S1. MP phylogenetic tree of five-locus alignment for FPYF3053-3056 in genus Diaporthe with Diaporthella corylina as an outgroup; Figure S2. ML phylogenetic tree of five-locus alignment for FPYF3053-3056 in genus Diaporthe with Diaporthella corylina as an outgroup.

Author Contributions: D.-H.Y. conceived the grant and designed the experiments; D.-H.Y., and T.L. collected the plant samples and identified the plant; X.S. and H.L. performed the experiment; D.-H.Y. organized the manuscript; G.S. advised research and revised manuscript. And G.D. managed laboratory jobs for this work and processed the submission.

Acknowledgments: This work was supported by Fundamental Research Funds of CAF (CAFYBB2017MA010, to D.-H.Y.). We thank Han Xu (Research Institute of Tropical Forestry, Chinese Academy of Forestry) for kindly helping with host plant identification, and thank Kaiying Wang (Research Institute of Forest Ecology, Environment and Protection) for taking part in the work on sample collection and fungal isolation. The authors sincerely appreciate the three peer reviewers' valued comments on the paper.

Conflicts of Interest: The authors declare no conflict of interest.

\section{References}

1. Kumar, G.; Chandra, P.; Choudhary, M. Endophytic fungi: A potential source of bioactive compounds. Chem. Sci. Rev. Lett. 2017, 6, 2373-2381.

2. Goyal, P.; Khanna, A.; Chauhan, A.; Chauhan, G.; Kaushik, P. In vitro evaluation of crude extracts of Catharanthus roseus for potential antibacterial activity. Int. J. Green Pharm. 2008, 2, 178-181. [CrossRef]

3. Ramya, S.; Govindaraji, V.; Kannan, K.N.; Jayakumararaj, R. In vitro evaluation of antibacterial activity using crude extracts of Catharanthus roseus L. (G.) Don. Ethnobot. Leafl. 2008, 12, 1067-1072. 
4. Kabesh, K.; Senthilkumar, P.; Ragunathan, R.; Kumar, R.R. Phytochemical analysis of Catharanthus roseus plant extract and its antimicrobial activity. Int. J. Pure Appl. Biosci. 2015, 3, 162-172.

5. Patil, P.J.; Ghosh, J.S. Antimicrobial activity of Catharanthus roseus-A detailed study. Br. J. Pharmacol. Toxicol. 2010, 1, 40-44.

6. Hanafy, M.; Matter, M.; Asker, M.; Rady, M. Production of indole alkaloids in hairy root cultures of Catharanthus roseus 1. and their antimicrobial activity. S. Afr. J. Bot. 2016, 105, 9-18. [CrossRef]

7. Lakra, N.S.; Koul, M.; Chandra, R.; Chandra, S. Histological investigations of healthy tissues of Catharanthus roseus to localize fungal endophytes. Int. J. Pharm. Sci. Rev. Res. 2013, 20, 205-209.

8. Pandey, S.S.; Singh, S.; Babu, C.S.V.; Shanker, K.; Srivastava, N.K.; Shukla, A.K.; Kalra, A. Fungal endophytes of Catharanthus roseus enhance vindoline content by modulating structural and regulatory genes related to terpenoid indole alkaloid biosynthesis. Sci. Rep. 2016, 6, 26583. [CrossRef] [PubMed]

9. Shi, Y.; Zhou, M.; Tang, Z.; Rao, L. Isolation and identification on endophytic fungus from Catharanthus roseus. J. Anhui Agric. Sci. 2008, 36, 12712-12713. [CrossRef]

10. Akpotu, M.O.; Eze, P.M.; Abba, C.C.; Umeokoli, B.O.; Nwachukwu, C.U.; Okoye, F.B.C.; Esimone, C.O. Antimicrobial activities of secondary metabolites of endophytic fungi isolated from Catharanthus roseus. J. Health Sci. 2017, 7, 15-22. [CrossRef]

11. Nair, D.N.; Padmavathy, S. Impact of endophytic microorganisms on plants, environment and humans. Sci. World J. 2014, 2014. [CrossRef] [PubMed]

12. Santos, P.J.C.D.; Savi, D.C.; Gomes, R.R.; Goulin, E.H.; Senkiv, C.D.C.; Tanaka, F.A.O.; Almeida, Á.M.R.; Galli-Terasawa, L.; Kava, V.; Glienke, C. Diaporthe endophytica and D. terebinthifolii from medicinal plants forbiological control of Phyllosticta citricarpa. Microbiol. Res. 2016, 186, 153-160. [CrossRef] [PubMed]

13. Tonial, F.; Maia, B.H.L.N.S.; Sobottka, A.M.; Savi, D.C.; Vicente, V.A.; Gomes, R.R.; Glienke, C. Biological activity of Diaporthe terebinthifolii extracts against Phyllosticta citricarpa. FEMS Microbiol. Lett. 2017, 364. [CrossRef] [PubMed]

14. Tanapichatsakul, C.; Monggoot, S.; Gentekaki, E.; Pripdeevech, P. Antibacterial and antioxidant metabolites of Diaporthe spp. Isolated from flowers of Melodorum fruticosum. Curr. Microbiol. 2017, 75, 476-483. [CrossRef] [PubMed]

15. Rakshith, D.; Santosh, P.; Satish, S. Isolation and characterization of antimicrobial metabolite producing endophytic Phomopsis sp. from Ficus pumila Linn. (Moraceae). Int. J. Chem. Anal. Sci. 2013, 4, 156-160. [CrossRef]

16. Chepkirui, C.; Stadler, M. The genus Diaporthe: A rich source of diverse and bioactive metabolites. Mycol. Prog. 2017, 16, 477-494. [CrossRef]

17. Strobel, G.A.; Dirkse, E.; Sears, J.; Markworth, C. Volatile antimicrobials from Muscodor albus, a novel endophytic fungus. Microbiology 2001, 147, 2943-2950. [CrossRef] [PubMed]

18. Singh, S.K.; Strobel, G.A.; Knighton, B.; Geary, B.; Sears, J.; Ezra, D. An endophytic Phomopsis sp. possessing bioactivity and fuel potential with its volatile organic compounds. Microb. Ecol. 2011, 61, 729-739. [CrossRef] [PubMed]

19. Qadri, M.; Deshidi, R.; Shah, B.A.; Bindu, K.; Vishwakarma, R.A.; Riyaz-Ul-Hassan, S. An endophyte of Picrorhiza kurroa Royle ex. Benth, producing menthol, phenylethyl alcohol and 3-hydroxypropionic acid, and other volatile organic compounds. World J. Microbiol. Biotechnol. 2015, 31, 1647-1654. [CrossRef] [PubMed]

20. Wang, K.; Strobel, G.; Yan, D.-H. The production of 1,8-cineole, a potential biofuel, from an endophytic strain of Annulohypoxylon sp. FPYF3050 when grown on agricultural residues. J. Sustain. Bioenergy Syst. 2017, 7, 65-84. [CrossRef]

21. White, T.J.; Bruns, T.D.; Lee, S.B.; Taylor, J.W.; Innis, M.A.; Gelfand, D.H.; Sninsky, J.J. Amplification and direct sequencing of fungal ribosomal rnagenes for phylogenetics. PCR Protoc. A Guide Methods Appl. 1990, 18, 315-322. [CrossRef]

22. Alves, A.; Crous, P.; Correia, A.; Phillips, A. Morphological and molecular data reveal cryptic species in Lasiodiplodia theobromae. Fungal Divers. 2008, 28, 1-13.

23. Santos, L.; Alves, A.; Alves, R. Evaluating multi-locus phylogenies for species boundaries determination in the genus Diaporthe. PeerJ 2017, 5, e3120. [CrossRef] [PubMed]

24. Glass, N.; Donaldson, G. Development of primer sets designed for use with the PCR to amplify conserved genes from filamentous ascomycetes. Appl. Environ. Microbiol. 1995, 61, 1323-1330. [PubMed] 
25. O'Donnell, K.; Cigelnik, E. Two divergent intragenomic rDNA ITS2 types within a monophyletic lineage of the fungus Fusarium arenonorthologous. Mol. Phylogenet. Evol. 1997, 7, 103-116. [CrossRef] [PubMed]

26. Udayanga, D.; Castlebury, L.A.; Rossman, A.Y.; Chukeatirote, E.; Hyde, K.D. Insights into the genus Diaporthe: Phylogenetic species delimitation in the D. eres species complex. Fungal Divers. 2014, 67, 203-229. [CrossRef]

27. Katoh, K.; Standley, D.M. Mafft multiple sequence alignment software version 7: Improvements in performance and usability. Mol. Biol. Evol. 2013, 30, 772-780. [CrossRef] [PubMed]

28. Lanfear, R.; Frandsen, P.B.; Wright, A.M.; Senfeld, T.; Calcott, B. Partitionfinder 2: New methods for selecting partitioned models of evolution for molecular and morphological phylogenetic analyses. Mol. Biol. Evol. 2017, 34, 772-773. [CrossRef] [PubMed]

29. Vaidya, G.; Lohman, D.; Meier, R. Sequencematrix: Concatenation software for the fast assembly of multi-gene datasets with character set and codon information. Cladistics 2011, 27, 171-180. [CrossRef]

30. Tamura, K.; Stecher, G.; Peterson, D.; Filipski, A.; Kumar, S. Mega6: Molecular evolutionary genetics analysis version 6.0. Mol. Biol. Evol. 2013, 30, 2725-2729. [CrossRef] [PubMed]

31. Stöver, B.C.; Müller, K.F. Treegraph 2: Combining and visualizing evidence from different phylogenetic analyses. BMC Bioinform. 2010, 11, 7. [CrossRef] [PubMed]

32. Ayob, F.W.; Simarani, K. Endophytic filamentous fungi from a Catharanthus roseus: Identification and its hydrolytic enzymes. Saudi Pharm. J. 2016, 24, 273-278. [CrossRef] [PubMed]

33. Momsia, P.; Momsia, T. Isolation, frequency distribution and diversity of novel fungal endophytes inhabiting leaves of Catharanthus roseus. Int. J. Life Sci. Biotechnol. Pharm. Res. 2013, 2, 82-87.

34. Kharwar, R.N.; Verma, V.C.; Strobel, G.; Ezra, D. The endophytic fungal complex of Catharanthus roseus (L.) g. Don. Curr. Sci. 2008, 95, 228-233. [CrossRef]

35. Manogaran, S.; Kannan, K.P.; Mathiyalagan, Y. Fungal endophytes from Phyllanthus acidus (L.) and Catharanthus roseus (L.). Int. Res. J. Pharm. 2017, 8, 86-89. [CrossRef]

36. Srinivasan, K.; Muthumary, J. Taxol production from Pestalotiopsis sp an endophytic fungus isolated from Catharanthus roseus. J. Ecobiotechnol. 2009, 1, 28-31.

37. Palem, P.P.C.; Kuriakose, G.C.; Jayabaskaran, C. An endophytic fungus, Talaromyces radicus, isolated from catharanthus roseus, produces vincristine and vinblastine, which induce apoptotic cell death. PLoS ONE 2015, 10, e0144476. [CrossRef] [PubMed]

38. Ayob, F.W.; Simarani, K.; Abidin, N.Z.; Mohamad, J. First report on a novel nigrospora sphaerica isolated from Catharanthus roseus plant with anticarcinogenic properties. Microb. Biotechnol. 2017, 10, 926-932. [CrossRef] [PubMed]

39. Rakotoniriana, E.F.; Chataigné, G.; Raoelison, G.; Rabemanantsoa, C.; Munaut, F.; El Jaziri, M.; Urveg-Ratsimamanga, S.; Marchand-Brynaert, J.; Corbisier, A.-M.; Declerck, S.; et al. Characterization of an endophytic whorl-forming Streptomyces from Catharanthus roseus stems producing polyene macrolide antibiotic. Can. J. Microbiol. 2012, 58, 617-627. [CrossRef] [PubMed]

40. Singh, D.; Rathod, V.; Singh1, A.K.; Haq, M.U.; Mathew, J.; Kulkarni, P. A study on extracellular synthesis of silver nanoparticles from endophytic fungi, isolated from ethanomedicinal plants Curcuma longa and Catharanthus roseus. Int. Lett. Nat. Sci. 2016, 57, 58-66. [CrossRef]

41. Tickoo, M.; Farooq, U.; Bhatt, N.; Dhiman, M.; Alam, A.; Khan, M.A.; Jaglan, S. Alterneriol: Secondary metabolites derived from endophytic fungi Alternaria spp. isolated from Catharanthus roseus. UJPAH 2015, 1, 15-17.

42. Tang, Z.; Rao, L.; Peng, G.; Zhou, M.; Shi, G.; Liang, Y. Effects of endophytic fungus and its elicitors on cell status and alkaloid synthesis in cell suspension cultures of Catharanthus roseus. J. Med. Plants Res. 2011, 5, 2192-2200.

43. Sunitha, V.H.; Devi, D.N.; Srinivas, C. Extracellular enzymatic activity of endophytic fungal strains isolated from medicinal plants. World J. Agric. Sci. 2013, 9, 01-09. [CrossRef]

44. Roy, S.; Banerjee, D. Broad spectrum antibacterial activity of granaticinic acid, isolated from Streptomyces thermoviolaceus NT1; an endophyte in Catharanthus roseus (L.) G. Don. J. Appl. Pharm. Sci. 2015, 5, $006-011$. [CrossRef]

45. De Pinho, P.G.; Goncalves, R.F.; Valent, P.; Pereira, D.M.; Seabra, R.M.; Andrade, P.B.; Sottomayor, M. Volatile composition of Catharanthus roseus (L.) G. Don using solid-phase microextraction and gas chromatography/mass spectrometry. J. Pharm. Biomed. Anal. 2009, 49, 674-685. [CrossRef] [PubMed] 
46. Aziz, S.; Saha, K.; Sultana, N.; Khan, M.; Nada, K.; Afroze, M. Comparative studies of volatile components of the essential oil of leaves and flowers of Catharanthus roseus growing in bangladesh by GC-MS analysis. Indian J. Pharm. Biol. Res. 2015, 3, 6-10. [CrossRef]

47. Bier, M.C.J.; Medeiros, A.B.P.; Soccol, C.R. Biotransformation of limonene by an endophytic fungus using synthetic and orange residue-based media. Fungal Biol. 2017, 121, 137-144. [CrossRef] [PubMed]

48. Bertrand, S.; Schumpp, O.; Bohni, N.; Monod, M.; Gindro, K.; Wolfender, J.-L. De novo production of metabolites by fungal co-culture of Trichophyton rubrum and Bionectria ochroleuca. J. Nat. Prod. 2013, 76, 1157-1165. [CrossRef] [PubMed]

49. Dickschat, J.S. Fungal volatiles-A survey from edible mushrooms to moulds. Nat. Prod. Rep. 2017, 34, 310-328. [CrossRef] [PubMed]

50. Garzoli, S.; Božović, M.; Baldisserotto, A.; Sabatino, M.; Cesa, S.; Pepi, F.; Vicentini, C.B.; Manfredini, S.; Ragno, R. Essential oil extraction, chemical analysis and anti-candida activity of Foeniculum vulgare miller-New approaches. Nat. Prod. Res. 2018, 32, 1254-1259. [CrossRef] [PubMed]

51. Dai, J.; Zhu, L.; Yang, L.; Qiu, J. Chemical composition, antioxidant and antimicrobial activities of essential oil from Wedelia prostrata. EXCLI J. 2013, 12, 479-490. [CrossRef] [PubMed]

52. Cosge, B.; Turker, A.; Ipek, A.; Gurbuz, B.; Arslan, N. Chemical compositions and antibacterial activities of the essential oils from aerial parts and corollas of Origanum acutidens (Hand.-Mazz.) Ietswaart, an endemic species to turkey. Molecules 2009, 14, 1702-1712. [CrossRef] [PubMed]

53. Espinosa-García, F.J.; Langenheim, J.H. Effects of sabinene and $\gamma$-terpinene from coastal redwood leaves acting singly or in mixtures on the growth of some of their fungus endophytes. Biochem. Syst. Ecol. 1991, 19, 643-650. [CrossRef]

54. Verma, R.S.; Joshi, N.; Padalia, R.C.; Singh, V.R.; Goswami, P.; Verma, S.K.; Iqbal, H.; Chanda, D.; Verma, R.K.; Darokar, M.P.; et al. Chemical composition and antibacterial, antifungal, allelopathic and acetylcholinesterase inhibitory activities of cassumunar-ginger. J. Sci. Food Agric. 2018, 98, 321-327. [CrossRef] [PubMed]

55. Rachitha, P.; Krupashree, K.; Jayashree, G.; Gopalan, N.; Khanum, F. Growth inhibition and morphological alteration of Fusarium sporotrichioides by Mentha piperita essential oil. Pharmacogn. Res. 2017, 9, 74-79. [CrossRef]

56. Moghaddam, M.; Pourbaige, M.; Tabar, H.K.; Farhadi, N.; Hosseini, S.M.A. Composition and antifungal activity of peppermint (Mentha piperita) essential oil from Iran. J. Essent. Oil Bear. Plants 2013, 16, 506-512. [CrossRef]

57. Strobel, G. The story of mycodiesel. Curr. Opin. Microbiol. 2014, 19, 52-58. [CrossRef] [PubMed] 